\title{
O QUE OS OLHOS E O CORAÇÃO VEEM E SENTEM: TRÊS ENCONTROS COM ARTE E EDUCAÇÃO MATEMÁTICA
}

\author{
WHAT THE EYES AND THE HEART SEE AND FEEL: THREE \\ MEETINGS WITH ART AND MATHEMATICALEDUCATION
}

\author{
João Carlos Pereira de Moraes \\ Pós-Doutorado em Educação (UEPG), professor da Universidade Federal do Pampa \\ (UNIPAMPA) Jaguarão - RS, Brasil \\ joaomoraes@unipampa.edu.br
}

\begin{abstract}
Resumo: O presente artigo tem o objetivo de elencar divergências e convergências entre alguns autores que se debruçam sobre a temática Arte e Educação Matemática, sendo eles Zaleski Filho, Franco e Mendes. Tal escolha deve-se à relevância dos mesmos no campo da Educação Matemática e sua relação com a Arte. Para realização da investigação, foram selecionados trabalhos dos pesquisadores com a temática e analisados em suas perspectivas teóricometodológicas. Como política de escrita, escolheu-se o modelo de entrevistas ficcionais, perante a ideia de abordar de forma mais sistemática as intenções dos autores. Como resultado, notam-se três abordagens diferenciais: (1) releitura da obra através do conhecimento matemático; (2) Investigação de práticas sociais mobilizadoras de cultura matemática; (3) Método estético, aplicação no cotidiano.
\end{abstract}

Palavras-Chave: Arte. Educação Matemática. Interdisciplinaridade. Pesquisadores.

Abstract: This article aims to list divergences and convergences between some authors who focus on the theme Art and Mathematical Education, being them Zaleski Filho, Franco and Mendes. Such choice is due to their relevance in the field of Mathematical Education and its relationship with Art. In order to carry out the investigation, researchers' works with the theme were selected and analyzed in their theoretical-methodological perspectives. As a writing policy, the fictional interview model was chosen, given the idea of addressing the authors' intentions in a more systematic way. As a result, three differential approaches are noted: (1) rereading the work through mathematical knowledge; (2) Investigation of social practices that mobilize mathematical culture; (3) Aesthetic method, application in daily life.

Keywords: Art. Mathematical Education. Interdisciplinarity. Researchers.

Para citar - (ABNT NBR 6023:2018)

MORAES, João Carlos Pereira de. O que os olhos e o coração veeme sentem: Três encontros com arte e educação matemática. Eccos - Revista Cientifica, São Paulo, n. 53, p. 1-16, e16615, abr./jun. 2020. Disponível em: https://doi.org/10.5585/eccos.n53.16615. 


\section{Introdução}

Àquele que inicia a leitura, digo que este artigo é uma construção inventiva. Além da intenção inicial, elencar divergências e convergências entre alguns autores que se debruçam sobre a temática Arte e Educação Matemática, parte da primazia de problematizar o próprio processo de escrita de um artigo científico.

Nesse sentido, posso dizer que dois elementos caminham paralelamente nesse trabalho. O primeiro deles e essencial consiste na leitura dos trabalhos de quatro autores com publicações significativas na área que relacionam Arte e Educação Matemática, levantando diferenças e/ou aproximações entre eles.

Os autores elencados para análise foram: (1) Dirceu Zaleski Filho (UNICID), autor do livro "Matemática e Arte" (2013a); Valdeni Soliani Franco (UEM), que propõe palestras, como "As Geometrias não Euclidianas na Arte e na Matemática" (2013a); (3) Iran Abreu Mendes (UFRN), organizador de uma edição especial da Revista de Matemática, Ensino e Cultura (REMATEC) sob o título “Arte, Matemática e Educação Matemática” (2012).

O segundo elemento é a escolha para a escrita deste artigo, que se dá por meio de entrevistas ficcionais. O objetivo é fomentar uma intenção de todo leitor ter um encontro com sua referência. 'E se eu pudesse conversar com Zaleski, Mendes e Franco, agora, nesta altura da noite, o que eu perguntaria?". Nesse sentido o texto foi escrito no modelo pergunta e resposta, sendo as perguntas minhas indagações nas leituras das obras e as respostas possíveis inferências a partir das publicações dos autores.

Nas seções subsequentes, narro meus encontros imaginativos com os pesquisadores acima mencionados. Assim, trago as quatro entrevistas criadas por meio das minhas leituras e uma síntese delas.

\section{Entrevistas $^{1}$ entre Arte e Educação Matemática}

Daqui em diante, estarei vis-à-vis com quatro pesquisadores do campo da Educação Matemática. Eles são referência quando o assunto é Arte e Educação Matemática no Brasil. Zaleski Filho, Franco e Mendes são professores de matemática que resolveram trabalhar, cada um conforme a sua perspectiva, com a temática. Autores que se dedicam à docência e à pesquisa na área do ensino de Matemática, apontando os benefícios da relação interdisciplinar com a Arte. 


\section{a) Zaleski Filho: a Arte como objeto na Educação Matemática}

Pedagogo, Professor de Matemática e Mestre em Educação, Arte e História da Cultura, Dirceu Zaleski Filho leciona nos cursos de Pedagogia e Matemática na Universidade Cidade de São Paulo (UNICID). Para a entrevista, entre os seus trabalhos, utilizamos como suporte: a dissertação Arte e Matemática em Mondrian (2009), na qual ele realiza uma pesquisa sobre a aproximação da Arte e da Matemática na obra do pintor Piet Mondrian (1872-1944); o livro "Matemática e Arte" (2013a), pertencente à coleção Tendências em Educação Matemática², que revela possíveis benefícios ao ensino das relações entre a História da Matemática e a História da Arte; e o artigo "Matemática e Arte: uma perspectiva necessária" (2013b), resultado da comunicação apresentada no XI ENEM, com reflexões embasadas em sua dissertação de mestrado.

Pesquisador JC: Professor Zaleski, quais as vantagens de relacionar Arte $e$ Matemática para discutir Educação Matemática?

Zaleski Filho: Inicialmente, é preciso considerar que as relações interdisciplinares entre Arte e Matemática já se justificam, uma vez que "estas duas áreas do conhecimento [aparecem] juntas desde os primeiros registros feitos pelo homem pré-histórico nas cavernas" (2013b, p. 1), o que é, se pararmos para pensar, de grande valia para construir ligações entre elas. Por outro lado, vejo na Arte uma possibilidade e um poder de contextualização do ensino da geometria em Matemática (2009). Isso eu expresso em meu livro e dissertação. Neles, eu contextualizo saberes da Matemática ora por intermédio da própria Arte ora por sua história.

JC: Em seus trabalhos aparece, diversas vezes, o termo "interdisciplinaridade”. Como o senhor compreende e o utiliza em seus estudos?

ZF: Embora eu não explicite uma definição, a interdisciplinaridade ingressou em meus trabalhos como uma possibilidade de estabelecer relações entre o campo da Matemática e da Arte, de modo que o conhecimento gerado por elas auxiliasse na resolução de problemas do cotidiano. Na minha proposta, ela adquire o papel de um instrumento para o ensino dos conteúdos matemáticos.

JC: Pode nos dar um exemplo?

ZF: No capítulo VII do meu livro (2013a), trago dois fatos atuais da relação entre Arte e Matemática que servem de exemplo. O primeiro é o caso do matemático Celso José da Costa que, ao descobrir uma das superfícies mínimas da matemática, utilizou-se da Arte e do computador para propor uma representação de sua equação. Já o segundo se refere ao professor Paulus Gerdes, que analisou os desenhos de um povo angolano, criando, a partir dos 
ornamentos, inferências científicas sobre matrizes cíclicas. Ambas as histórias apontam que a Arte seria um recurso útil no campo da Matemática, capaz de apoiar a resolução de problemas que venham a surgir na atualidade.

JC: Em sua forma de conceber as relações entre Arte e Educação Matemática, qual é o papel exercido pela Arte?

ZF: Na minha concepção, a arte torna-se, além de um instrumento e um recurso, como já disse anteriormente, um meio para propagar a comunicação do saber matemático, ou seja, ela passa a ser uma representação da representação matemática da realidade.

JC: Em seus escritos, o senhor utiliza também o termo "matemática visual”. Seria possível nos relatar o que significa e qual a relação desse termo com a Arte e a Matemática?

ZF: O termo Matemática Visual não é uma denominação criada por mim. Foi elaborado e utilizado por Michele Emmer (2005 apud ZALESKI, 2009, p. 6), e pauta-se na aproximação entre Arte e Matemática com o uso do computador. Na Matemática Visual, a Matemática adquire características de processo de criação, que visa produzir e compreender "novas formas visuais utilizando o grafismo eletrônico e como estas formas têm influenciado os artistas, formas essas que podem ser chamadas de novas imagens matemáticas e artísticas” (2009, p. 141).

JC: Como o senhor transpôs a Matemática Visual para o ensino de matemática?

ZF: Primeiro, eu me aproximei de alguns referenciais teóricos do campo da história da Matemática, como Boyer (1974) e Eves (1992), e, em seguida, de autores da história e teoria da Arte, entre eles Cauquelin (2005) e Chipp (1988). Após me apropriar das leituras, relacioneias com os estudos de Freire (1999a; 1999b; 2001) na educação e, por fim, com as pesquisas da Educação Matemática de D’Ambrósio (1986; 1990; 2001;2008a; 2008b). Assim, a Matemática Visual, antes pertencente à matemática pura, entra em consonância com as ideias matemáticas nas diversas ações do homem e, ainda, com a presença e importância dessa disciplina no cotidiano da Cultura Ocidental.

JC: Em suas publicações são citados Freire e D’Ambrósio. Por que a escolha desses autores para a sua pesquisa?

$\mathbf{Z F}$ : Antes da resposta, cabe ressaltar dois pontos. O primeiro é que procuro práticas que ofereçam uma aprendizagem com base na realidade para os conteúdos curriculares da matemática, pois compreendo que elas são capazes de reforçar e motivar a educação científica. O segundo consiste no meu pressuposto de estudo, que somos seres inacabados que, por termos consciência disso, somos passíveis de educação e transformação. Dito isso, respondo à sua pergunta. Dos estudos de Freire, interessa-me sua concepção de aprendizado. Um aprendizado 
que emerge da busca que o sujeito faz para a sua vida, dos seus conhecimentos prévios e das ressignificações feitas com/sobre eles. Já as discussões de Ubiratan D’Ambrosio (1990 apud ZALESKI, 2009) remontam, em meu pensamento, à Educação Matemática, que atende a tais princípios. Ou seja, uma Educação Matemática entre a antropologia cultural e a matemática institucional, capaz de atribuir ao ensino novos enfoques, apontando para uma diversidade cultural de valores, como a questão estética da Arte. Apenas no uso desse ponto de vista, na Educação Matemática, "é aberto um espaço para a aproximação entre Matemática e Arte" (2009, p. 144).

JC: De acordo com sua proposta de Arte e Educação Matemática, qual é a função do artista que produz um quadro?

ZF: O artista é aquele que dá forma ao conhecimento matemático, ele traz para a obra os saberes da área vigente em sua cultura. Isso é perceptível nos trabalhos de Cézanne e Mondrian, por exemplo. Enquanto Cézanne 'utilizou como instrumentos as leis 'abstratas' da Geometria que conduziram as formas naturais aos seus modelos mais simples: a esfera, o cone e o prisma" (2013b, p. 7), Mondrian expressou "sua arte por meio das cores fundamentais e de conceitos matemáticos para, no seu entender, representar o entorno por meio da sua expressão interior que tentou representar a essência do representado" (2009, p. 143).

JC: Estamos conversando sobre questões teóricas. O senhor pode dar um exemplo de sua proposta na prática docente?

ZF: Em minha dissertação, eu elaborei um Plano de Aula que visa o trabalho em sala (2009, p. 147). Ele consiste numa atividade referente ao Quadro 1, de Mondrian, em que busco discutir o conteúdo de segmentos de reta para o $6^{\circ}$ ano do Ensino Fundamental. Se você observar os objetivos e o desenvolvimento da ação (Zaleski aponta para a página 147 de sua dissertação. A citação foi retirada e figura na página a seguir, ao lado do quadro de Mondrian), o primeiro passo é a escolha das pinturas. Isso acontece de acordo com o conteúdo matemático que se quer ensinar, o que, neste caso, é o ensino de segmento de reta. Veja que o Quadro 1, de Mondrian, pode suscitar mais diretamente um discurso sobre o conteúdo que se quer trabalhar. Vamos para o contato com os alunos. Na sala de aula, eu proponho que a pintura seja visualizada para, em seguida, identificar nela padrões matemáticos. Depois, isolamos tais padrões e exploramos suas propriedades. Seria uma espécie de processo de decodificação da imagem em conceitos matemáticos. A obra de arte traria, então, esse lócus aos estudantes, demonstrando que é possível motivar e aprender a matemática institucional. Por fim, depois de conhecer e discutir a organização matemática que rege a pintura, os estudantes teriam condição para realizar uma releitura da obra. O que se configura num exercício prático do saber matemático 
em questão, ou seja, eles deverão pôr em ação as proposições e as propriedades aprendidas sobre os segmentos de reta.

\section{b) Franco: a Arte como caminhos para a Educação Matemática}

Professor e Doutor em Matemática, Valdeni Soliani Franco discute as temáticas: geometria não euclidiana, tecnologias no ensino e Arte e Matemática. Para nossa conversa com o pesquisador, nos embasamos em quatro dos seus trabalhos: os artigos "Análise da Geometria de Algumas Obras de Arte Utilizando o GeoGebra" (FRANCO, 2013a) e "Perspectiva - Arte ou Matemática", escrito em parceira (FRANCO; FERREIRA; SANTOS, 2013); e as palestras “As Geometrias não Euclidianas na Arte e na Matemática" (2013b) e "O Uso da Arte nas Aulas de Matemática” (2013c).

Pesquisador JC: Professor Valdeni, o que o faz entender que as relações entre Arte e Matemática são profícuas ao ensino de Matemática?

Valdeni Franco: Antes de responder à sua pergunta, destaco dois pontos que considero relevantes na relação Arte e Matemática: (1) a questão da percepção do mundo, que insere o sujeito num contexto histórico, dotando-o da capacidade de interação, modificação e criação do conhecimento; e, (2) a representação com linguagens diferentes, que propõe que tanto conhecimentos geométricos quanto artísticos são formas diferentes de representar o mesmo mundo. Ao entrelaçar a relação Arte e Matemática com esses polos, consigo interações entre os conhecimentos do estudante e os aspectos histórico-geométricos da representação, que são cruciais na elaboração de sentido no ensino de Matemática. Dessa forma, as relações interdisciplinares entre Arte e Matemática são profícuas na medida em que "estimula(m) a percepção, a criatividade, a imaginação" do estudante (GUSMÃO, 2013, p. 46 apud FRANCO, 2013b, p. 1), bem como ressaltam e conectam modos de representar a realidade no campo artístico e matemático.

JC: Seu trabalho remonta ao conceito de interdisciplinaridade. Como ele posto é concebido em suas pesquisas?

VF: Não trago nenhum delineamento específico sobre o termo, nem acredito que seja necessário. Mas considero pertinente tratá-lo enquanto união de saberes, com o objetivo de compreender de maneira aprofundada a sociedade. Creio que a interdisciplinaridade exerce o papel de conectar Arte e Matemática na busca de aproximações para um entendimento mais abrangente do mundo em que vivemos.

JC: Pode nos dar um exemplo? 
VF: Na palestra "As Geometrias não Euclidianas na Arte e na Matemática" (2013b), eu produzo um indício de tal ideia. Apresento o caso dos fractais, uma relação entre Geometria não Euclidiana e Arte. Demonstro, no estudo, que a grande quantidade de objetos que vemos é composta por formas irregulares, e não por retas, cones ou esferas, e que, portanto, sua redução aos padrões da Geometria Euclidiana seria inadequada no ensino da matemática. Para solucionar o problema, sugeri o uso dos fractais, uma vez que eles compõem uma representação mais precisa de tais formas. Assim, tanto a natureza quanto a Arte trazem pistas para o conhecimento matemático de fractais, capazes de aproximá-los da realidade do estudante, como no estudo de representação de montanhas e oceanos.

\section{JC: Como o senhor vê essa relação entre Arte e Matemática?}

VF: Considero o ato de relacionar Arte e Matemática um processo que integra tanto as informações matemáticas da obra de arte quanto as informações culturais e históricas que o aluno traz para ela. Por conseguinte, pensar na realização de um estudo nesse campo requer a utilização, algumas vezes, da própria história, outras, dos próprios conceitos da Geometria a ser estudada, ou ainda de ambos.

JC: E a matemática, como ela participa dessa relação interdisciplinar?

VF: A Matemática seria um saber organizador da representação num dado momento histórico. Acredito que ela se insere nos outros saberes, instituindo formas e ordenamentos, elaborando o modo que constituímos o espaço à nossa volta. Um exemplo disso é "a topologia [que] tem sido utilizada por arquitetos contemporâneos para a obtenção do binômio forma/estrutura, considerando-a no uso de formas complexas e de superficies não planares" (2013d, p. 11). Isso me faz entender que, nos dias atuais, a topologia tem produzido padrões de representar e organizar o mundo ao nosso redor, como na arquitetura.

JC: Quais autores e princípios o professor utiliza para pensar Arte e Educação Matemática?

VF: Atualmente, tenho me aproximado de referenciais teóricos do campo da história da Geometria, como Coxetter (1968), e da história da Arte, entre eles, Proença (2008) e Ducher (2001). Trago também para minhas reflexões autores que se debruçam sobre a aplicação da Matemática na Arte, como Sperling (2008), e ainda pesquisadores que enfatizam a interdisciplinaridade dos dois campos, dos quais eu cito: Flores (2002, 2003), Cifuentes (2005) e Gusmão (2013). Enfim, meu intuito é apontar o papel que a Matemática exerce na aplicação do conhecimento artístico e possibilitar o acesso ao conhecimento matemático pelo método estético, que é "uma abordagem subjetiva e sensorial da realidade" (GUSMÃO, 2013, p. 48). 
JC: Então, quando o senhor relaciona Matemática e Arte, procura práticas que ofereçam uma abordagem mais subjetiva e sensorial da Matemática?

VF: Sim, após minhas leituras de Cifuentes (2005) e Gusmão (2013), percebo que a Arte proporciona certo "prazer", que não se fixa apenas à emoção, mas que provoca e estimula o conhecimento matemático pelo lado sensível do homem. Assim, nas relações com a Matemática, o sensível interage com o racional elaborando uma estética da matemática, capaz de mobilizar o aprendizado e, se associada aos conhecimentos cotidianos do aluno, potencializa mais um eixo de significação no ensino da disciplina.

JC: A partir de sua proposta, qual a função do artista na relação Arte e Matemática?

VF: O artista é o sujeito posicionado num local de interação, que se utiliza de conhecimentos matemáticos e dos modos de viver de uma época para criar sua Arte. Veja, por exemplo, as pinturas de Escher. O pintor utilizou de modelos da Geometria Hiperbólica, mais precisamente, do Modelo de Disco de Poincaré para construir a obra Círculo Limite IV, de 1960 (2013b). Na ação interdisciplinar, percebemos que o artista deixou marcas matemáticas formais que se caracterizam como pistas, oferecendo uma possibilidade para refazermos o trajeto de produção da imagem e da construção do seu sentido histórico e cultural.

JC: Como é possível trabalhar com essas questões em sala de aula?

VF: Imaginemos conteúdos referentes à Topologia, relacionando-os com fotos do Museu de Arte Contemporânea de Niterói (2013b). Primeiro, eu realço o conhecimento matemático, elaborando uma explanação da diferença entre Geometria não Euclidiana e Topologia, bem como de algumas noções contidas na última: "Noções de longe/perto, de vizinhança; dentro/fora (interior/exterior); aberto/fechado; separado/unido (conexo desconexo); contínuo/descontínuo; orientado/não orientado" (2013b, p. 7).

Em seguida, relaciono as questões geométricas elásticas da topologia com o Museu de Arte Contemporânea de Niterói. Enfatizo, também, que a arquitetura pensada com os saberes da Topologia preserva as propriedades dos objetos, mesmo que estes sofram torções, encolhimentos e distensões em sua forma. "Esses termos e conceitos advindos da Topologia trazem para o campo da arquitetura uma quarta dimensão, que antes era desprezada. Esta dimensão é o tempo que está implícito ao movimento" (2013c, p. 11).

Embora eu me preocupe com o conceito matemático, não posso abandonar a constituição histórica e cultural que condiz com o momento de produção da obra, nem com as questões sociais que advêm com ela no cotidiano. Para pensar sobre isso, posso trazer características pertencentes ao trabalho do arquiteto Oscar Niemeyer, por exemplo. 


\section{c) Mendes: a Arte como fonte histórica e cultural da Educação Matemática}

Professor de Matemática e Doutor em Educação pela Universidade Federal do Rio Grande do Norte (UFRN), Iran Abreu Mendes pesquisa possíveis contribuições da História e Cultura da Arte para o campo da Educação Matemática. Entre os seus trabalhos sobre o tema, e para a constituição da entrevista, partimos dos artigos "O Octógono Artístico, Sagrado e Geométrico na Capela de São João Batista em Belém do Pará" (2012a), “Arte e ciência na Amazônia no século XVIII: algumas contribuições de José Antonio Landi e João Ângelo Brunelli" (2010) e "Ensino de conceitos geométricos, medidas e simetria: por uma educação (etno)matemática com arte" (2008a); dos capítulos do livro "Da arte geométrica na cerâmica marajoara e suas potencialidades didáticas" (2012b) e "Matemática, ciência, arte e jogo" (2003); da organização da edição especial da Revista de Matemática, Ensino e Cultura (REMATEC), que recebeu o nome de Arte, Matemática e Educação Matemática (MENDES; FLORES, 2012); e do projeto de pesquisa em desenvolvimento "Sociedade, Cognição e Cultura: por uma educação etnomatemática com arte".

Pesquisador JC: Professor Iran, quais os benefícios de criar relações entre Arte e Matemática para o campo da Educação Matemática?

Iran Mendes: Quando você relaciona Arte e Matemática, são suscitados sentidos mais amplos e profundos ao conhecimento matemático que está em construção no ambiente escolar. Você demonstra que nas produções de uma sociedade existem "convergências de padrões cognitivos nas criações geométricas, bem como conexões de saberes interdisciplinares na criação artística e matemática" (2008a, p. 36). Por outro lado, a Matemática pertencente a essa relação será "mais agradável e acessível para a maioria dos estudantes do que a matemática envolvida em aplicações científicas" (2008a, p. 38), já que suas ações remeterão a diálogos entre práticas e saberes, alicerçados no contexto social, cognitivo e cultural ao qual o aluno pertence (2001).

JC: $O$ senhor pode explicar melhor a passagem quando se refere ao contexto social, cognitivo e cultural?

IM: No anseio de explicar os acontecimentos cotidianos, as sociedades produzem estratégias cognitivas que culminam em "representações do seu modo de ver e viver no mundo" (2008a, p. 36). Tais representações emergem materialmente de diversas maneiras, como a Arte. Assim, a representação artística com "suas linhas, formas e padrões geométricos configuram expressões poliformais que comunicam e evidenciam aspectos sociocognitivos e culturais de 
cada grupo social que os elaborou" (2008a, p. 36). Isso acarreta que, para pensar Arte e Educação Matemática, não posso me desvincular dos conceitos de cultura, história e cognição.

JC: Como o senhor tem utilizado tais conceitos em suas pesquisas?

IM: Atualmente, norteio-me por um modelo de pesquisa histórica pautado na investigação de práticas sociais mobilizadoras de cultura matemática, em que considero pertinente a investigação de um conjunto articulado de ações sociais intencionais, realizadas individualmente ou coletivamente pelos sujeitos integrantes de uma comunidade de práticas culturais e/ou profissionais, que só adquire significação no contexto do sistema de atividade do qual participam (MENDES; NOBRE, 2009, p. 135).

Tenho utilizado também, nesse campo, diversos autores: "Veyne (2008), Burke (2005), Foucault (2000), Funari (2005), Bacelar (2005) e Aróstegui (2006), que propõem a reconstrução histórica e interpretativa como fonte de produção de conhecimento histórico" (p. 135).

JC: Então, como posso pensar essas compreensões de História na pesquisa em Educação Matemática? E, especificamente, no campo da Arte e da Educação Matemática?

IM: A história pode se configurar para a Educação Matemática enquanto um agente de cognição, uma vez que a análise de questões resolvidas durante o percurso histórico de uma sociedade serve de instrumento cognitivo, útil enquanto padrão de busca de soluções para interrogações atuais no ensino da Matemática (2008b). Já para a relação Arte e Matemática, proponho um estudo por meio da investigação histórica, fundamentado na análise dos movimentos cognitivos instituídos na sociedade humana e na aplicação deles como princípio e reflexão de questões de ensino e aprendizagem da Matemática escolar. As próprias histórias da Arte (re)construídas podem elaborar um material histórico-artístico. Elas são capazes de auxiliar no entendimento da matemática praticada e na reflexão sobre "estratégias de formulação do conhecimento, sua organização, codificação e sistematização no contexto da sociedade e da cultura, bem como as suas formas de incorporação aos sistemas educativos" (2008b, p. 7-8).

JC: De certa forma, seu entendimento não se assemelha à etnomatemática?

IM: Sim, assemelha-se. Procuro explorar em minhas pesquisas aspectos históricos, antropológicos e artísticos da matemática presente nas produções de diversas sociedades. Um exemplo é o estudo que realizei com a sociedade Marajoara e Icoaraciense. Por meio das convergências de padrões cognitivos nas pinturas dessas civilizações, eu encontrei indícios de estruturas geométricas universalizantes ou, como denomina Gerdes (1991 apud MENDES, 2008a, p. 36), um pensamento geométrico. 
JC: De acordo com sua proposta de Arte e Educação Matemática, quais os sentidos adotados para a Arte e para a Matemática?

IM: Em minha proposta, tanto a Arte quanto a Matemática são manifestações cognitivas que trazem consigo um pensamento geométrico. Sendo uma manifestação humana, a Arte seria fruto de um jogo de símbolos e formas geométricas, constituída em tempo e espaço distintos e de formas diferentes (2003). Só para exemplificar, temos uma diversidade de produções religiosas e arquitetônicas que se diferem em sua constituição, conforme o momento e lugar em que são elaboradas. Assim, associo a Arte não somente à forma (2012a), já que, isolada de um contexto histórico e cultural, qualquer manifestação artística perde o seu valor enquanto potencial de significação para a aprendizagem matemática. Quanto ao saber matemático, não penso muito diferente. Para mim, a Matemática é um "conhecimento historicamente construído a partir de indagações enfatizadas na busca da solução para os problemas enfrentados pela humanidade" (2008b, p. 9). Enfim, considero que a relação entre Arte e Matemática amplia, quando interligadas num plano multicultural, as habilidades matemáticas dos estudantes, conectando saberes locais a um contexto global e vice-versa.

JC: Nessa relação entre Arte e Educação Matemática, como o senhor pressupõe a função do artista?

IM: O artista é aquele que coloca em movimento as características formais e simbólicas da manifestação cognitiva de uma sociedade, respondendo, através de sua arte, aos desejos e dúvidas do período que está inserido. Assim o fez José Antonio Landi, na Capela de São João Batista, em Belém do Pará, ao atender a uma arquitetura para a demarcação de limites territoriais entre Portugal e Espanha (2012a). E também os artistas que confeccionaram a Cerâmica Marajoara, na Ilha do Marajó, no município de Ponte das Pedras no Pará, que colaboraram com o firmamento da cultura local, mediante manifestações exteriores (2012b).

JC: Como trazer essas relações nas práticas para a sala de aula?

IM: Respondo com um exemplo, um estudo etnomatemático que realizei na cultura marajoara (MENDES, 2008a; MENDES; FERRETE, 2003). A pesquisa ocorreu, digamos assim, em dois momentos: no primeiro, após uma análise, constatou-se uma forte presença da simetria por translação e rotação nas representações pictóricas do grupo; e, no segundo, um estudo histórico e cultural do pensamento geométrico da comunidade. Mediante os dois momentos, levantei um padrão cognitivo nas obras, além de uma base explicativa do pensamento simbólico do grupo em questão (2008a). Em sala de aula, eu utilizaria essa pesquisa da seguinte maneira: veja a tampa de uma panela de barro produzida na cultura marajoara (imagens em Mendes (2008a)). 
Olhando para a peça, traçando um eixo vertical, de simetria, percebemos três movimentos que organizam aspectos simétricos na peça: o padrão 1 sofre uma rotação de $180^{\circ}$ em torno do eixo vertical; o padrão 2 sofre uma rotação de $180^{\circ}$ em torno da própria figura e outra de $180^{\circ}$ em torno do eixo vertical; o padrão 3 sofre uma rotação de $180^{\circ}$ em torno do eixo vertical (2008a, p. 41).

Com esse estudo matemático da obra, eu consigo discutir a noção de simetria e de distribuição perfeita da arte no espaço e, deste modo, relacionar a Arte com a Matemática escolar. Se eu fosse o professor, para encerrar a atividade, proporia um "exercício criativo para que os alunos construam novas formas geométricas, a partir das combinações das formas tradicionais já conhecidas deles, bem como explorar as noções de área e perímetro" (2008a, p. 41).

\section{Possível consideração final: uma tentativa de elaboração entre abordagens ou um levantamento de convergências e diferenças}

Nas seções anteriores, criamos entrevistas sobre diferentes abordagens no campo da Arte e da Educação Matemática, produzidas a partir das publicações de quatro autores: Zaleski Filho, Franco, Mendes e Flores. E para sistematizar algumas divergências e convergências entre os autores, elaboramos a tabela abaixo. Nele, expomos algumas sínteses que consideramos relevantes para a compreensão daqueles que queiram estudar Arte e Educação Matemática, apontando assim a nossa fala final neste trabalho.

Tabela 1 - Comparativo de abordagens de Arte e Educação Matemática

\begin{tabular}{|c|c|c|c|}
\hline \multicolumn{2}{|c|}{ COMPARATIVO DE ABORDAGENS } & \multicolumn{2}{|c|}{ - ARTE E EDUCAÇÃO MATEMÁTICA } \\
\hline & Zaleski Filho & Mendes & Franco \\
\hline $\begin{array}{c}\text { Trabalhos } \\
\text { Analisados }\end{array}$ & 3 & 5 & 4 \\
\hline Arte/Imagem & Objeto & Manifestação cognitiva & Representação \\
\hline Matemática & $\begin{array}{l}\text { Matemática como } \\
\text { proces so de criação, } \\
\text { matemática visual }\end{array}$ & $\begin{array}{c}\text { Conhecimento } \\
\text { historicamente } \\
\text { construído a partir de } \\
\text { indagações enfatizadas } \\
\text { na busca da solução para } \\
\text { os problemas enfrentados } \\
\text { pela humanidade }\end{array}$ & $\begin{array}{l}\text { Saber organizador da } \\
\text { repres entação num } \\
\text { dado momento } \\
\text { histórico }\end{array}$ \\
\hline Artista & $\begin{array}{c}\text { Aquele que dá forma ao } \\
\text { conhecimento } \\
\text { matemático }\end{array}$ & $\begin{array}{l}\text { Aquele que coloca em } \\
\text { movimento as } \\
\text { características formais e } \\
\text { simbólicas da } \\
\text { manifestação cognitiva } \\
\text { de uma sociedade, } \\
\text { respondendo, através de } \\
\text { sua arte, aos desejos e }\end{array}$ & $\begin{array}{l}\text { Sujeito que representa } \\
\text { conhecimentos } \\
\text { matemáticos, a partir } \\
\text { do seu local de } \\
\text { interação e dos modos } \\
\text { de uma época. }\end{array}$ \\
\hline
\end{tabular}




\begin{tabular}{|c|c|c|c|}
\hline & & $\begin{array}{c}\text { dúvidas do período em } \\
\text { que está inserido. }\end{array}$ & \\
\hline Interdis ciplinaridade & $\begin{array}{l}\text { Instrumento para a } \\
\text { resolução de problemas. }\end{array}$ & $\begin{array}{l}\text { Produtor de sentidos } \\
\text { mais amplos e profundos } \\
\text { ao conhecimento em } \\
\text { construção. }\end{array}$ & $\begin{array}{l}\text { União de saberes, } \\
\text { vis ando a uma } \\
\text { compreensão } \\
\text { aprofundada da } \\
\text { realidade. }\end{array}$ \\
\hline $\begin{array}{c}\text { Relação entre Arte e } \\
\text { Matemática }\end{array}$ & $\begin{array}{l}\text { Contextualização do } \\
\text { ensino de geometria }\end{array}$ & $\begin{array}{l}\text { Análise dos movimentos } \\
\text { cognitivos instituídos na } \\
\text { sociedade humana e sua } \\
\text { aplicação como princípio } \\
\text { e reflexão de questões de } \\
\text { ensino e aprendizagem } \\
\text { da matemática escolar. }\end{array}$ & $\begin{array}{l}\text { Processo que integra } \\
\text { informações } \\
\text { matemáticas da obra de } \\
\text { arte - processo } \\
\text { perceptivo - e as } \\
\text { informações culturais e } \\
\text { históricas que o aluno } \\
\text { traz para ela - processo } \\
\text { sociocognitivo. }\end{array}$ \\
\hline $\begin{array}{l}\text { Intuito da Relação } \\
\text { Arte e Matemática }\end{array}$ & $\begin{array}{c}\text { Apontar as ideias } \\
\text { Matemáticas nas divers as } \\
\text { ações do homem e a } \\
\text { presença e importância } \\
\text { da matemática no } \\
\text { cotidiano da cultura } \\
\text { ocidental }\end{array}$ & $\begin{array}{c}\text { Elaborar um material } \\
\text { histórico-artístico capaz } \\
\text { de auxiliar no } \\
\text { entendimento da } \\
\text { matemática praticada e } \\
\text { na reflexão sobre } \\
\text { estratégias de formulação } \\
\text { de conhecimento, sua } \\
\text { organização, codificação } \\
\text { e sistematização no } \\
\text { contexto da sociedade e } \\
\text { da cultura. } \\
\end{array}$ & $\begin{array}{l}\text { Apontaro papel que a } \\
\text { matemática exerce na } \\
\text { aplicação do } \\
\text { conhecimento artístico } \\
\text { e a possibilidade do } \\
\text { acesso ao } \\
\text { conhecimento } \\
\text { matemático por um } \\
\text { método estético. }\end{array}$ \\
\hline $\begin{array}{l}\text { Justificativa para } \\
\text { Arte e Matemática }\end{array}$ & $\begin{array}{l}\text { Ambos os } \\
\text { conhecimentos aparecem } \\
\text { juntos desde os primeiros } \\
\text { regis tros feitos pelo } \\
\text { homem pré-histórico nas } \\
\text { cavernas }\end{array}$ & $\begin{array}{l}\text { Uma matemática mais } \\
\text { agradável e acessível } \\
\text { para a maioria dos } \\
\text { estudantes do que uma } \\
\text { matemática envolvida } \\
\text { em aplicações científicas. }\end{array}$ & $\begin{array}{l}\text { Estimular a percepção, } \\
\text { a criatividade e a } \\
\text { imaginação do aluno e } \\
\text { ressaltar e conectar } \\
\text { modos de representar a } \\
\text { realidade no campo } \\
\text { artístico e matemático. }\end{array}$ \\
\hline $\begin{array}{l}\text { Abordagem } \\
\text { metodológica }\end{array}$ & $\begin{array}{c}\text { Releitura da obra através } \\
\text { do conhecimento } \\
\text { matemático. }\end{array}$ & $\begin{array}{l}\text { Investigação de práticas } \\
\text { sociais mobilizadoras de } \\
\text { cultura matemática. }\end{array}$ & $\begin{array}{c}\text { Método estético; } \\
\text { aplicação no cotidiano. }\end{array}$ \\
\hline
\end{tabular}

Fonte: A pesquisa.

\section{Notas}

\footnotetext{
${ }^{1}$ Embora já tenha destacado, vale lembrar que não fiz uma entrevista direta com os pesquisadores, mas a partir das leituras de suas produções, elaborando possíveis respostas.

2 A coleção Tendências em Educação Matemática busca apresentar tópicos na área que tenham tido um desenvolvimento substancial nas últimas décadas e que possamse transformar em novas tendências curriculares dos ensinos fundamental, médio e universitário.
} 


\section{Referências}

BOYER, C. B. História da Matemática. Tradução de Elza Gomide. São Paulo: Edgard Blücher, 1974.

CAUQUELIN, A. Teorias da arte. Tradução de Rejane Janowitzer. São Paulo: Martins Fontes, 2005.

CHIPP, H. B. Teorias da arte. Tradução de Waltensir Dutra et al. São Paulo: Martins Fontes, 1988.

CIFUENTES, J. C. Uma via estética de acesso ao conhecimento matemático. Boletim GEPEM, Rio de Janeiro, n. 46, p. 55-72, 2005.

COXETER, H. S. M. Non-Euclidean Geometry. 5. ed. Toronto: University of Toronto Press, 1968.

D’AMBROSIO, U. Da realidade à ação: reflexões sobre Educação “e” Matemática. São Paulo: Summus Editorial, 1986.

D’AMBROSIO, U. Educação Matemática: da teoria à prática. Campinas: Papirus, 2008b.

D’AMBROSIO, U. Etnomatemática. São Paulo: Ática, 1990.

D'AMBROSIO, U. Etnomatemática: elo entre as tradições e a modernidade. Belo Horizonte: Autêntica, 2001. (Coleção Tendências em Educação Matemática).

D’AMBROSIO, U. Uma história concisa da Matemática no Brasil. São Paulo: Vozes, 2008a.

DUCHER, R. Características dos estilos. Tradução de Maria Armentina Galvão. São Paulo: Martins Fontes, 2001.

EVES, H. História da Matemática para uso em sala de aula - Geometria. Tradução de Higino H. Domingues. São Paulo: Atual, 1992.

FLORES, C. R. Abordagem histórica no ensino de matemático: o caso da representação em perspectiva. Revista Contra-Pontos, Itajaí, v. 1, n. 1, p. 377- 388, set./dez. 2002.

FLORES, C. R. Olhar, saber, representar: ensaios sobre a representação em perspectiva. 2003. 188 f. Tese (Doutorado em Educação - Ensino de Ciências, Centro de Ciências da Educação) - Universidade Federal de Santa Catarina, Florianópolis, 2003.

FRANCO, V. S. Análise da Geometria de algumas obras de arte utilizando o GeoGebra. In: Congreso Latinoamericano GeoGebra, Argentina, 2013. Presidência Roque Sáens Peña: UNCAUS, 2013c. v. 1. 
FRANCO, V. S. As Geometrias não Euclidianas na Arte e na Matemática. 2013. (Apresentação de Trabalho/Conferência ou palestra). In: ENCONTRO NACIONAL DE EDUCAÇÃ̃O MATEMÁTICA, 11., 2013. Anais [...]. ISSN 2178-034X. Apresentação em PPT.

FLORES, C. R. Olhar, Saber, Representar: ensaios sobre a representação em perspectiva. 2003. 188f Tese (Doutorado em Educação - Ensino de Ciências, Centro de Ciências da Educação) - Universidade Federal de Santa Catarina, Florianópolis, 2003.

FLORES, C. R. Abordagem histórica no ensino de matemático: o caso da representação em perspectiva. Revista Contra-Pontos, Itajaí, v. 1, n. 1, p. 377- 388, set./dez. 2002.

FRANCO, V. S. As Geometrias não Euclidianas na Arte e na Matemática. 2013a. (Apresentação de Trabalho/Conferência ou palestra). Anais do XI Encontro Nacional de Educação Matemática - ISSN 2178-034X.

FRANCO, V. S. Apresentação em PPT As Geometrias não Euclidianas na Arte e na Matemática. 2013b. (Apresentação de Trabalho/Conferência ou palestra). Anais do XI Encontro Nacional de Educação Matemática - ISSN 2178-034X.

FRANCO, V. S. Análise da Geometria de algumas obras de arte utilizando o GeoGebra. In: Congreso Latinoamericado GeoGebra Argentina 2013. Presidencia Roque Sáens Peña: UNCAUS, 2013c. v. 1.

FRANCO, V. S.; FERREIRA, L.; SANTOS, T. S. dos. Perspectiva - Arte ou Matemática. In: ENCONTRO NACIONAL DE EDUCAÇÃO MATEMÁTICA, 11., 2013. Anais do XI Encontro Nacional de Educação Matemática - ISSN 2178-034X.

FREIRE, P. Educação e mudança. Rio de Janeiro: Paz e Terra, 2001.

FREIRE, P. Pedagogia do oprimido. Rio de Janeiro: Paz e Terra, 1999a.

FREIRE, P. Educação como prática da liberdade. Rio de Janeiro: Paz e Terra, 1999b.

GUSMÃO, L. D. Educação Matemática pela Arte: uma defesa da educação da sensibilidade no campo da Matemática.26/02/2013. 149f. Dissertação. Universidade Federal do Paraná, Curitiba. 2013.

MENDES, I. A. O octógono artístico, sagrado e geométrico na Capela de São João Batista em Belém do Pará. REMATEC. Revista de Matemática, Ensino e Cultura (UFRN), v. 10, p. 106$124,2012 \mathrm{a}$.

MENDES, I. A. Da Arte Geométrica na Cerâmica Marajoara e suas Potencialidades Didáticas. In: Iran Abreu Mendes; Isabel Cristina Rodrigues de Lucena. (Org.). Educação Matemática e Cultura Amazônica: fragmentos possíveis. 1ed.Belém - PA: Editora Açaí, 2012b, v. p. 203-227. 
MENDES, I. A.; FLORES, C. R. Editorial. Natal - RN: EDUFRN, 2012 (Texto de Editorial). (organização da Revista Matemática, Ensino e Cultura - REMATEC). REMATEC/Ano 7/ n.10/ Janeiro de 2012, p.01 ISSN 1980-3141. Arte, Matemática e Educação Matemática.

MENDES, I. A. Arte e Ciência na Amazônia no século XVIII: algumas contribuições de José Antonio Landi e João Ângelo Brunelli. Anais VIII Seminário Nacional de História da Matemática, v. 1, p. 49-65, 2010.

MENDES, I. A.; NOBRE, S. João Ângelo Brunelli: um padre matemático e astrônomo italiano participante da comissão demarcadora de limites da Amazônia na Era Pombalina. Revista Brasileira de História da Matemática - Vol. 9 no18 (outubro/2009-março/2010) pág.133-152 Publicação Oficial da Sociedade Brasileira de História da Matemática ISSN 1519-955X.

MENDES, I. A. Ensino de conceitos geométricos, medidas e simetria: por uma educação (etno)matemática com arte. Revista cocar (UEPA), v. 02, p. 35-47, 2008 a.

MENDES, I. A. A história como agente de cognição na Educação Matemática. Revista Matemática \& Ciência, ano 1, n.2, p. 7-18, jul. 2008b.

MENDES, I. A. Matemática, ciência, arte e jogo. In: ALMEIDA, M. da C. de; KNOBB, M.; ALMEIDA, A. M. (Org.). Polifônicas ideias. Por uma ciência aberta. Porto Alegre: Editora Sulina, 2003, v. único, p. 154157.

MENDES, I. A.; FERRETE, R. B. Investigando a cerâmica marajoara e reorientando a matemática escolar. In: XVI Encontro de Pesquisa Educacional das regiões Norte e Nordeste - XVI EPENN,2003, Aracaju. Anais EPENN 2003 - Educação, Pesquisa e Diversidade Regional. Aracaju: Editora UFS, 2003.

MENDES, I. A. Sociedade, Cognição e Cultura: por uma Educação Etnomatemática com arte. Projeto de Pesquisa. Belém: UEPA, 2001.

PROENÇA, G. História da Arte. São Paulo: Editora Ática, 2008.

SPERLING, D. M. Entre conceitos, metáforas e operações: convergências da topologia na arquitetura contemporânea. Gestão \& Tecnologia de Projetos, [s. l.], v. 3, n. 2, nov. 2008. ZALESKI FILHO, D. A Arte e Matemática em Mondrian. 2009. 168 f. Dissertação (Mestrado em Educação, Arte e História da Cultura) - Universidade Presbiteriana Mackenzie, São Paulo, 2009.

ZALESKI FILHO, D. Matemática e Arte. Belo Horizonte: Autêntica, 2013a. v. 1, 184 p.

ZALESKI FILHO, D. Matemática e Arte: uma perspectiva necessária. In: ENCONTRO NACIONAL DE EDUCAÇÃO MATEMÁTICA, 11., 2013, Curitiba. Anais [...]. Curitiba 2013b. v. 1. 